\title{
Chinese Contemporary Sculpture Spiritual Based on Traditional Culture*
}

\author{
ZHENG Miao, PENG Ling-ling \\ Dalian University of Technology, Dalian, China
}

\begin{abstract}
For the purposes of Chinese Contemporary Sculpture, what we should see are the real cultural connotation and its cultural background behind it, rather than just comparing Chinese sculpture to Western art. It can be seen as a driving force in enlarging the influence of traditional culture. At the same time, it will make our contemporary sculptures have more long-term career developments and advancements. Therefore, we should find that our culture is able to be enjoyed by all over the world, because it has a huge difference to west culture. As the descendants of our nation, we should inherit our great culture and flourish it .This is not simply a display of traditional cultural symbols, it also gives us the possibility to understand humanistic ideas of understanding and recycling. Works not only brought out the beauty of the material, but also delivered a serene classical mood.
\end{abstract}

Keywords: contemporary sculpture, traditional culture, spirit

\section{Introduction}

In terms of the significance of traditional culture, We can say that all Confucianism history in the past produced today's cultures, which has become a tradition of culture, and the culture we are now trying to create will eventually become traditional culture after a certain amount of historical evolution. Thus, the traditional culture does not mean the same to fall behind. After the baptism of time, now we can see the great essence and worth of cultural heritage. Traditional culture should not only be remained on the exterior level, indeed, it should be understood in the perception of spiritual content. As the "Book of Changes" said: "Judging from astronomy, you can see the change in time; Judging from the humanities, you can see the change of the world" reflects the combination of natural law and the law of human relations, which reflects the great efforts of so many people. This is not simply a display of traditional cultural symbols, it also gives us the possibility to understand humanistic ideas of understanding and recycling. Works not only brought out the beauty of the material, but also delivered a serene classical mood. The art makes good use of the work itself and it gives people deep impression.

\footnotetext{
${ }^{*}$ Acknowledgements: This paper was supported by

(1) Social Science Foundation of Liaoning Province, China: Culture: Research on the Virtual Platform of Public Sculptures in University Campuses. (L13DWJ027);

(2) Social Science Foundation of Liaoning Province, China: Research on the Advantages and Modernization of Folklore Symbols in Liaoning Province Based on Aesthetic of Time. (L13DZX020);

(3) The Ministry of Education of Humanities and Social Science Project: Aesthetic of Time in Chinese Buddhism: Taking the Expression of Art in Daily Life for Example. (14YJC760046).

ZHENG Miao, lecturer, master, School of Architecture and Fine Art, Dalian University of Technology.

PENG Ling-ling, lecturer, Ph.D. candidate, School of Architecture and Fine Art, Dalian University of Technology.
} 


\section{Aesthetic Value Inherent in Traditional Sculpture}

\section{The Practicability, Utilitarian, and Decorative of Ancient Chinese Sculpture}

Ethical code has always been an important part of the Chinese culture, in ancient society, people always believe in God. Generally speaking, the ancient pottery, bronzes, jade, and lacquer wares are basically used for decoration and ritual, ultimately derived from the practicality of sculpture, and sculpture has a great significance in the development of the dynasties. Funerary objects are funerary goods, while sculptures occupy a larger proportion of the funerary articles. Shaping with plenty of decorative techniques can make the Buddha's shape more solemn. For example, in our shape of classical sculptures, lions evil always gives a very imposing, brave, and more sacrosanct psychological feeling to people, this is because the overall shape has a lot of decoration, which make them play a role as the lion architectural decoration (for example, see Figure 1).

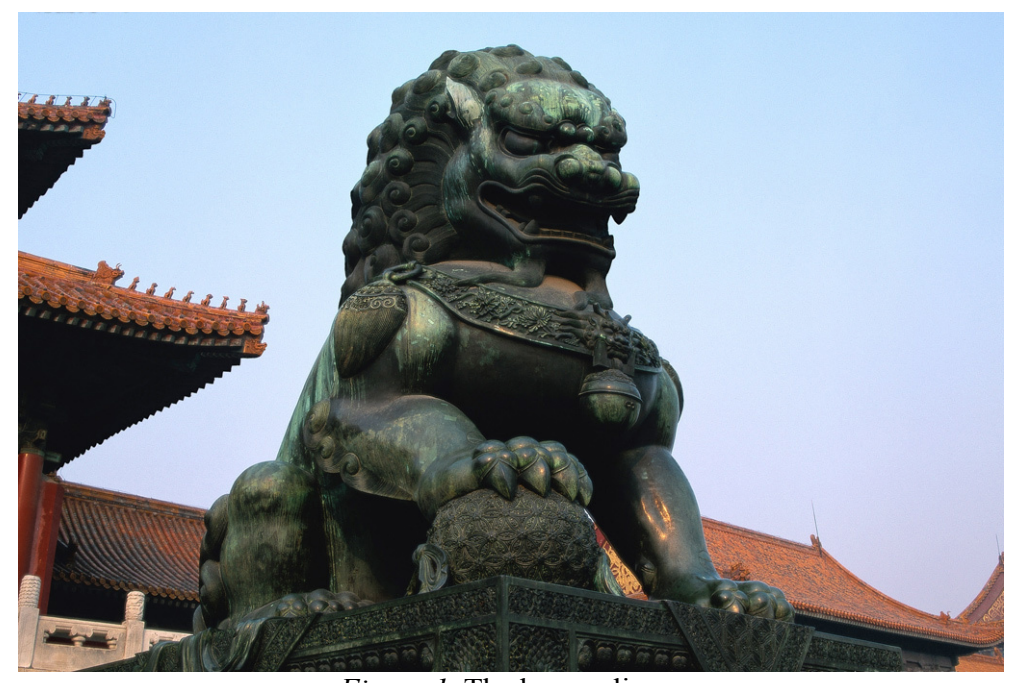

Figure 1. The bronze lions.

\section{The Characteristic "Line" and "Surface" of Chinese Traditional Sculpture}

As we all know, the integrated use of line, surface, and volume has a profound impact in the whole sculpture creation. The "line" in ancient Chinese sculpture has always had a very important role. For example, the main characteristic of Western Han Dynasty sculpture is the inner circle, and this is inherit from the styling features of the Warring States Period, which works not only had great power but also had rounded features. So when we learn the ancient sculpture, the first priority is to be familiar with a variety of molding methods and applied materials, and second is to appreciate the line and the relationship between surface and volume .Fully grasping this "form of business, meaning students form" spiritual connotation can help us inherit the traditional culture in a very effective way.

\section{The Expression in Ancient Chinese Painting Sculpture}

In traditional Chinese culture, performance art has always been stressed as the main spirit, and it has been committed to reach a higher level of image of transcendence. Therefore, we can say that in traditional Chinese arts, as products of evolution, the "Manner" is the long-standing special aesthetic charm of our nation history. Therefore, for the purposes of today's sculpture, traditional charm should not only be comprehended, but also be able to express their importance in a better way. 
In the history, both classical painting and sculptures originated in Chinese original arts and crafts. At the same time, both of them learned from each other and had developed a lot, even in the form of expression they had some thing in common. One of the Profession called "makeup case" is to improve the capacity and performance of the sculpture as a result of decorative painting. Western sculptures are completely different from the eastern sculpture, the first one has a strong sense of volume, and the other one only has the large volume. For example, in the expression of pleats, authors usually use incised way, but that is not the drawbacks of the expression of such a strong three-dimensional. This is why we are relatively smooth appearance of ancient sculpture. This feature, we can learn from the Han and Tang pottery, Dunhuang Mogao Grottoes Tang Song Maijishan plastic and plastic Buddhist statues, as well as plastic maid Taiyuan Jinci Song, Liao Huayansi Datong under plastic Buddha Temple, Shanxi Pingyao clear plastic, etc..Square charm is also to be presented in such painting and sculptures. Now, when we are going to create a classical sculpture, the first thing we should learn is the aesthetic point of view in our culture, rather than blindly comparing eastern sculpture with western art expression (for example, see Figure 2).

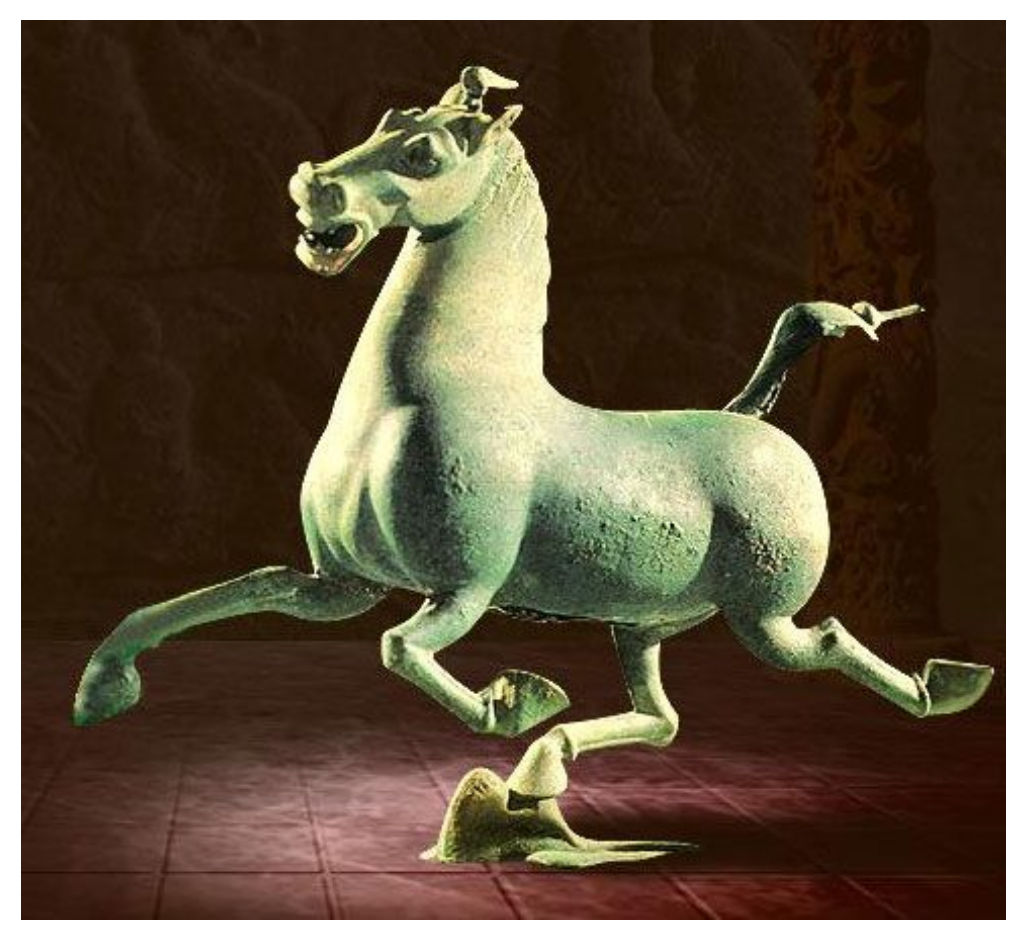

Figure 2. The horse stepped swallow.

\section{Ancient Chinese Sculpture Has Highly Sexual Imagery}

For thousands of years, Chinese sculptures and paintings through a long development and evolution have gradually become an independent form of artistic expression. For a long time, sculpture and painting are just two kinds of decorative arts, this is why the sculpture is more important than painting in the interaction between people and art. The creation of sculpture and painting is not pursuing "resemblance". This point is particularly evident in Chinese painting. Western painting stressed the need to accurately portray objects painting, however, Chinese painting is attached a lot to the basis of observing the imagination, which changes subjective processed into unique charm artistic image. 
From the large number of sculptures, we can see many intentionality characteristics. For example, Han and Tang pottery, Huo tomb stone, statues, and other ancient religions. They are same as Chinese paintings, which is not pursuit "resemblance". We need to look at the perspective of classical artistic aesthetic in a new way. In this case, when we appreciate the ancient sculptures, we would not like to enjoy the pursuit of realistic-Western sculpture and the life-like image of shapes.

Thus, we can see that China did so concise language of ancient sculpture, mainly because of the intentionality. Chinese ancient sculpture is always pursuit of the atmosphere, majestic momentum to create a unique artistic atmosphere, and thus make the work more interesting. In term of shaping the animals, ancient people usually use exaggeration methods; we can clearly feel this in the Han Dynasty in Sichuan Figurines and Huo tomb in Shishou. The work is not a pursuit for the animal's image realistic effects, but to express the worker's feelings of different creatures. And in Chinese art, such kind of artistic expression often has more tensions and impacts.

\section{The Application of Traditional Cultural Elements in Contemporary Sculpture}

As we all know, natural, simple, and subtle harmony are the main features of our oriental charm. From our traditional culture, we can see them really clearly. For example, Suzhou gardens and the Great Wall are typical in such style of building demonstrated. These colorful traditional elements can be used as the resources of sculpture creations today.

We can see this Chinese application and presentation elements in "rockery stone series" and Sui's "mantle". Therefore, for each one of our workers, the profound Chinese elements of sculpture are very worthwhile in terms of researching and thinking.

In order to understand the expression forms of traditional Chinese art, the best way is to start from the art of calligraphy. We can say that a good understanding of the essence of the art of calligraphy can help us learn the different forms of expression for understanding the context of the overall arts. First of all, as a modeling approach, the performance is closely related to sculpture. Secondly, as a culture, it can help each art creator to reach their artistic accomplishments. In short, the calligraphy can play a significant role to help push the creation of sculpture. Sculptor LIUYong-gang is always committed to the art of calligraphy; from his work, we can feel his literacy and artistic skills.

\section{Traditional Cultural Spirit Incontemporary Sculpture Reproduction}

In traditional Chinese culture, Taoism, Confucianism, and Buddhism are in one great integration, and they also derived from a variety of cultural branch. Under the influence of this culture, since ancient times, the performance of works of art and their appropriate symbols appear in the harmonious forms, in an attempt to show respect and reverence to all beings. However, at this point, Western culture is at the opposite side to China's traditional culture. What Western culture emphasis is to conquer nature, to become the masters of nature, while in the grasp of the nature inevitably will bring great material wealth. But even so, it also could not hide the lack of Western civilization and the cultural heritage of the deficiencies. For us, this has important significance in today's society; we should first recognize that maybe the acceptance of Western material technology is good for our society development, but we should not be affected by such a strong culture. Humanity is a increasing problem, 
which can unable to be escaped, and even though at the right time in the western world, economy, science, and technology have been developed, these problems can not be solved, either. Every one should bear in mind that traditional Chinese culture is more able to evoke the true spiritual haven for the whole world.

In this area, the sculptor who named JU Ming, from Taiwan, has a great achievement. He took the 70s century native Taiwanese culture as the entry points to his performance. We can find this expression in the work named "Tai Chi Series" (see Figure 3) and the work "World Series". These works are both from the essence of traditional Chinese culture, and he used the strength of character in shaping China. He always worked with nature, because he believes that his own life can bring the true feelings to him, which may be adopted in his work. "Tai Chi" is the essence of Chinese tradition culture; it is from the origin of the universe and reflects the running of life. ZHU Ming successfully used these complex and esoteric philosophy concepts to create his work. From this series of "Tai Chi", we can see the great ideas of classical Chinese philosophy of Heaven and its majestic great charm. This traditional charm and cultural heritage is worthwhile for every Chinese people to learn.

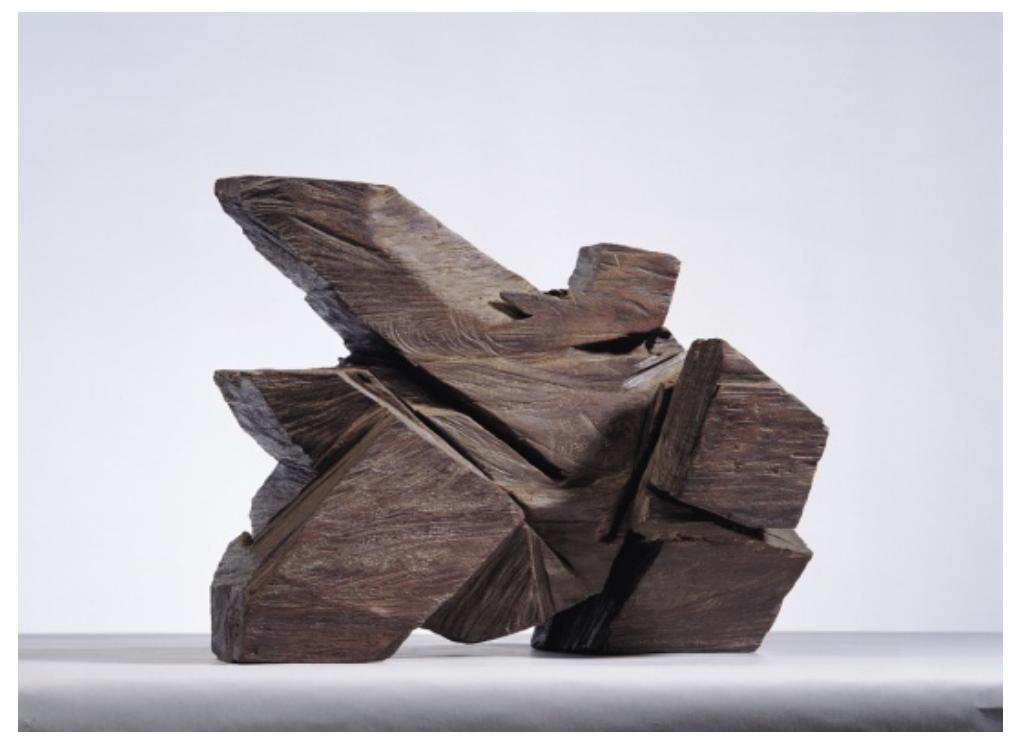

Figure 3. Sculpture $<$ Tai Chi $>$, JU Ming.

\section{Conclusion}

As for contemporary Chinese cultural orientation process, sculptor Mr. CAI Zhi-song pathfinder also has an innovative spirit to this area. His work named "Motherland" (see Figure 4) shows the Chinese characters in modern world. It gives every viewer a very deep impression. In modern society, people seem to be more satisfied in the pursuit of material. People seem to no longer care about the promotion of spiritual purity, the kind of meditation, meditation, nature, and man's classical humanistic spirit naturally becomes a precious legacy in today's society. "Motherland" adopts modern performance practices figures to show a strong culture of fortitude characters. The character's personality shows us the great Chinese culture, which is linked to good unity, so that we can get a strong feeling to the ancient civilizations. This is not simply a display of traditional cultural symbols, it also gives us the possibility to understand humanistic ideas of understanding and recycling. Works not only brought out the beauty of the material, but also delivered a serene classical mood. The art makes good use of the work itself and it gives people deep impression. It is a great piece of work that everyone will never forget. 


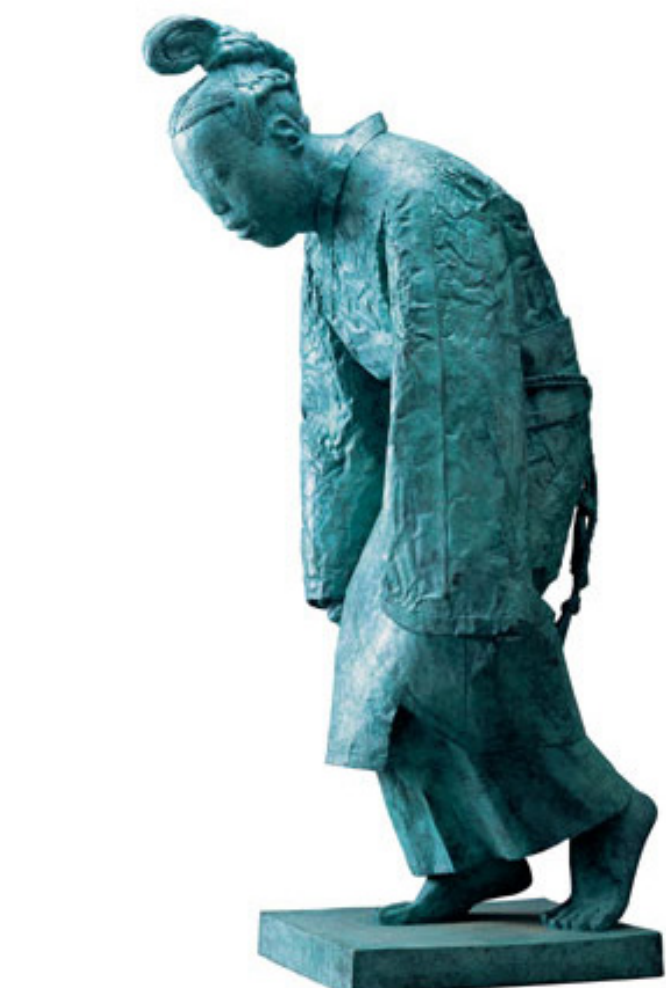

Figure 4. Sculpture < Motherland: the Wind $>$, CAI Zhi-song.

When we are going to understand more of Chinese traditional art forms, it is significant to learn Chinese philosophy. It is the core of Chinese culture, and it also reflects the development of all art. Therefore, the expression of philosophy has a close relationship with sculpture, in other words, the expression of sculpture can be seen as an art form, and it can also be an outward expression of philosophical thought. So, when we can understand our ancient sculptures, we can also deeply appreciate our philosophy, which is very important for our cultural development.

In this case, when we create art, we should first take the true meaning of our traditional culture into consideration, while also express the true meaning of art, and then, the effect of the work will be very affecting.

\section{References}

WU, W. S. (2007). Poetics of culpture. NanJing: Nanjing University Press.

HUO, B. Y. (2007). Double foundation. Changchun: Jilin Art Publishing House.

WANG, N. N. (2008). Sculpture-art. TaiYuan: Shanxi Province Education Publishing House.

DING, Y. P. (2005). Art-culturology. Beijing: Culture And Art Publishing House.

JIAO, X. T. (2010). New figurative sculpture. Chongqing: Chongqing Publishing House.

HE, L. P. (2010). Seven holes for sculpture. Beijing: People's Publishing House.

SUN, Z. H. (2011). The history of Chineses ancient sculpture. Beijing: China Youth Publishing House.

WANG, W. J. (2010). The development of Chinesesculpture in global vision. Journal of Huma-nities, 5, 105-111. 